
contract DE-AC05-84OR21400. Accordingly. the U.S. Governinent reteins a nonexcluaive, royalty-free license to publish or reproduce the published torm of this contribbtion, or allow others to do so, for U.S. Government purposes.

\title{
Wall conditioning and leak localization in the Advanced Toroidai Facility*
}

\author{
R. A. Langley, J. C. Glowienka, P. K. Mioduszewski, M. Murakami, \\ T. F. Rayburn, J. E. Simpkins, S. W. Schwenterly, and J. L. Yarber
}

Oak Ridge National Laboratory, Oak Ridge, Tennessee 37831-8072

\section{DISCLAIMER}

This report was prepared as an account of work sponsored by an agency of the United States Government. Neither the United States Government nor any agency thereof, nor any of their employees, makes any warranty, express or implied, or assumes any legal liability or responsiprocess disclosed, or represents that or usefulness of any information, apparatus, product, or ence herein to any specific commer that its use would not infringe privately owned rights. Refermanufacturer, or otherwise does rot product, process, or service by trade name, trademark, mendation, of favoring by the rot necessarily constitute or imply its endorsement, recomand opinions of authors expressed herein Government or any agency thereof. The views United States Government or any agency thereof necessarily state or reflect those of the 
Wall conditioning and leak localization in the Advanced Toroidal Facillty

R. A. Langley, J. C. Glowienka, P. K. Mioduszewski, M. Murakami,

T. F. Rayburn, J. E. Simpkins, S. W. Schwenterly, and J. L. Yarber

Oak Ridge National Laboratory, Oak Ridge, Tennessee 37831-8072

The Advanced Toroidal Facility (ATF) vacuum vessel and its internal components have been conditioned for plasma operation by baking, discharge cleaning with hydrogen and helium, and gettering with chromium and titanium. The plasma-facing surface of ATF consists mainly of stainless steel with some graphite; the outgassing area is dominated by the graphite because of its open porosity. Since this situation is somewhat different from that in other fusion plasma experiments, in which a single material dominates both the outgassing area and the plasma-facing area, different cletining and conditioning techniques are required. The situation was aggravated by air leaks in the vacuum vessel, presumably resulting from baking and from vibration during plasma operation. The results of the various cleaning and conditioning techniques used are presented and compared on the basis of residual gas analysis and plasma performance. A technique for detecting leaks from the inside of the vacuum vessel is described; this technique was developed because access to the outside of the vessel is severely restricted by external components. 


\section{Introduction}

The Advanced Toroidal Facility (ATF) is an optimized torsatron designed to further develop the stellarator concept and to study toroidal confinement physics issues such as second stability, E-field effects, disruption-free operation, and fundamental transport mechanisms. The importance of cleaning and conditioning the vacuum vessel to ensure successful plasma operation was recognized during the design phase. Therefore, baking and glow discharge cleaning (GDC) were incorporated and implemented in the initial phase of operation. Because there was some uncertainty atout the effect of impurities on plasma operation in the helical configuration of ATF, provisions were made to use gettering if needed to achieve the desired levels of plasma cleanliness. During the startup phase, it was demenstrated that wall conditioning and vacuum vessel cleanliness were more important in currentless, stellarator-type devices than in tokamaks. 1,2

The ATF facility and its operational characteristics are described in detail in Ref. 3; only thie pumping, baking, glow discharge, and gettering systems for the vacuum vessel are described here. This paper reviews the recent operational exper:ence of ATF (through August 1989), which has included chromium and titanium gettering, and describes a method that was successfully developed for localizing leaks by sensing helium from inside the vacuum vessel.

The ATF vacuum vessel, shown in Fig. 1, is fabricated from nonmagnetic stainless steel plates welded with Inconel filler metal. The complicated shape is designed to accommodate the two helical torsatron windings. Heating sources, pumping system components, and diagnostics are coupled to the device through 48 ports of 3 different sizes. The high-vacuum pumping system for the vacuum vessel (see Fig. 2) consists of three 2200-L/s turbopumps in parallel, each backed with a forepump. The effective speed of the pumping station at the 
vessel was measured to be $2500 \mathrm{~L}$ s. Two residual gas analyzers (RGAs) are installed in the pumping station for gas analysis. Table I gives the pertinent surface areas for the various components in ATF.

Baking of the vacuum vessel is accomplished by inductive coupling of ac power via excitation of the helical field (HF) windings. This provides heating at a rate that brings the vessel to its maximum allowable temperature of $150^{\circ} \mathrm{C}$ in $=20 \mathrm{~min}$. After initial heating, the maximum vessel temperature is held between 140 and $150^{\circ} \mathrm{C}$ by switching the induction heating on for $150 \mathrm{~s}$ every $360 \mathrm{~s}$. Baking is carried out overnight; a complete bake cycle lasts about $5 \times 10^{4} \mathrm{~s}$. The inductive coupling of the HF coils to the vessel is nonuniform and leads to large temperature variations on the vessel. When the hottest portion of the vessel is at $150^{\circ} \mathrm{C}$, the coclest portion is near $75^{\circ} \mathrm{C}$. To compensate for this nonuniformity, heating tapes are used to heat the torus appendages. The heating system is described in detail in Ref. 4.

The GDC system 5 uses either hydrogen or deuterium gas. The normal operating conditions are an anode voltage of $600 \mathrm{~V}$, an anode current of $2 \mathrm{~A}$, and an operating pressure of $2 \mathrm{mTorr}$. This provides a particle flux to the wall of about $2 \times 10^{13}$ ions $/ \mathrm{cm}^{2} \mathrm{~s}$. During induction heating of the vacuum vessel, the HF coil currents produce a magnetic field that significantly reduces the glow discharge volume, so effective cleaning does not take place during the heating phase; however, it does take place during the cooling phase. The cycling of the heating system is thus incorporated in an efficient method of cleaning and conditioning that effectively permits simultaneous baking and GDC. Cleaning and conditioning procedures are discussed in Sec. II.

Beginning in the initial operating phase, leaks have developed during plasma operation and baking, presumably because of vibration and the expansion and contraction of the vacuum vessel. The high priority placed on plasma operation has li:nited the time available for leak finding and repair. Some of 
these leaks were large (about $10^{-4}$ Torr-L/s) and difficult to find with the conventional technique of leak checking from outside the vacuum vessel because of interference from external components, so gettering was implemented to keep plasma impurity levels low enough so that plasma studies could be conducted until sufficient time could be allocated to find and repair the leaks. The successful application of a unique method devised to localize these leaks is discussed in Sec. III.

\section{Cleaning and conditioning}

The typical procedure for cleaning and conditioning ATF after an air vent is to pump the system to the $10^{-6}$-Torr range and then remove the adsorbed water from the Thomson scattering viewing system (TSVS), shown in Fig. 2, by baking the anodized aluminum baffles at a temperature near $150^{\circ} \mathrm{C}$ for several bake cycles. Baking is done only at night so that hands-on maintenance (e.g., installation and calibration of diagnostics and plasma heating systems) can be carried out during normal working hours. Figure 3 is a typical plot of system pressure vs time for the second bake cycle after a vacuum vessel opening. The maximum pressure reached during baking is shown in Fig. 4 for four consecutive bake cycles. As the number of cycles increases, the maximum pressure during a cycle decreases until a plateau is reached. The amount of $\mathrm{H}_{2} \mathrm{O}$ released during a bake cycle, as estimated by RGA scans, is given in Table II. The results suggest that baking at $150^{\circ} \mathrm{C}$ can effectively remove water from anodized aluminum.

When the maximum pressure begins to reach a plateau, additional cleaning and conditioning techniques are implemented. The usual procedure is a combination of baking the vacuum vessel and its appendages and GDC with hydrogen, which removes a considerable amount of oxygen, mostly as $\mathrm{H}_{2} \mathrm{O}$, 
from the system. During this procedure, the limiters, the diagnostic graphite plate, and the ICRF antenna are also cleaned and conditioned to some extent. Neutral-beam-injected plasmas obtained following this cleaning and conditioning procedure exhibit better performance, as demonstrated by the time to radiative collapse (Fig. 5) and the peak stored energy (Fig. 6). These plasma parameters were chosen to illustrate the effect of plasma impurities because they are believed to be strongly influenced by the global impurity content of the plasma.

Although the observed improvements were encouraging, the rate of progress was judged inadequate to reduce the plasma impurity levels to the desired values in a timely manner. Since increasing the time for cleaning and conditioning almost always reduces the time available for plasma operation, we decided to try chromium gettering as a cleaning procedure. This technique has been used successfully to improve plasma performance in a timely manner. 6 The chromium gettering produced substantial improvement, es shown in Figs. 5 and 6 for two chromium getters that covered about $30 \%$ of the vessel area with thin chromium films. Following this improvement, two more sources were installed to provide about $50 \%$ coverage. Again, significant improvement was observed, although control of the fuel gas was difficult. Since chromium does not pump hydrogen significantly, ${ }^{7}$ we switched from chromium to titanium to gain better control of the hydrogen feed gas. This change resulted in additional improvement in the plasma parameters. After the data of Figs. 5 and 6 were obtained, plasma parameter scans were done to optimize the stored energy. It was found that a significant improvement in the stored energy could be obtained by adjusting the feed gas. When this paramater was adjusted to its optimum value, the stored energy was increased to $21.5 \mathrm{~kJ}$.

At present, we getter belore each day of operation. This provides additional pumping of about $25,000 \mathrm{~L} / \mathrm{s}$. The pumping speed continually decreases throughout the day as the gettered surface becomes saturated and is com. 
pletely saturated after about $4 \mathrm{~h}$ of plasma operation. Residual gas analysis after cleaning and conditioning with baking and GDC yields parial pressures of $1 \times 10^{-6}$ Torr $\mathrm{N}_{2}, 0.7 \times 10^{-6}$ Torr $\mathrm{H}_{2} \mathrm{O}$, and $2 \times 10^{-8}$ Torr $\mathrm{Ar}$, which are the major impurity gases. After titanium gettering, significant reductions (about a factor of $1 \mathrm{CO}$ ) in $\mathrm{N}_{2}$ and $\mathrm{H}_{2} \mathrm{O}$ are observed. Levels of Ar remain about the same because Ar is not gettered by titanium and is always present as a constituent of the air leaks. During and after a plasma discharge, $\mathrm{CH}_{4}$ and $\mathrm{H}_{2} \mathrm{O}$ are the major gas impunities produced. In a typical discharge, about $2 \times 10^{-5}$ Torr-L of $\mathrm{CH}_{4}$ and about $5 \times 10^{-6}$ Torr-L of $\mathrm{H}_{2} \mathrm{O}$ are produced.

\section{Leak locallzation and repair}

As noted earlier, leaks developed in the vacuum vessel during the initial operating period. Those that were reasonably accessible were located and repaired. There was an indication of one or more air leaks located under an HF coil; with conventional leak detection techniques, this could only be localized to a general area that comprised about one-tenth of the surface of the vessel $(=4$ $\mathrm{m}^{2}$ ). The leak was in the range of $10^{-4}$ atm $\mathrm{cm}^{3} / \mathrm{s}$, as determined from rate-ofnise measurements of the $\mathrm{N}_{2}$ partial pressure and calculations based on the base pressure and pumping speed. The suspected area was completely covered by an HF coil and the structural shell. A number of different leak detection methods were considered. These included (1) a remotely manipulated ion gauge placed inside the vacuum vessel to detect the air jet entering the vessel through the leak, (2) a movable sniffer attached to a leak detector (LD) inside the vessel to sample helium flooded over the outside of the vessel with the vessel only partially pumped, ${ }^{9}$ and (3) a suction plate attached to an LD that could be placed on the internal surfaces of the vacuum vessel while helium was flooded over the outside of the vessel. We chose the third method because it 
required a minimal amount of additional equipment and could be prepared within the time available and because we were successful in devising a technique to easily and reliably attach various sizes and shapes of suction plates to the inner surface of the vacuum vessel. A more detailed description of the leak localization technique and repair is given in Ref. 10.

The interior of vessel surface is generally quite smooth, but many rough areas remain from weld grinding operations. As seen in Fig. 1, there are also many inside and outside comers and compound-curved surfaces. Owing to these conditions, commercial suction plates proved unworkable. After several trials, we developed an arrangement that could be used for essantially all conditions encountered. This arrangement consisted of a suction plasie formed from a piece of $0.32-\mathrm{cm}$-thick gum-rubber sheet, with a hard plastic nozzle sealed into a hole in the sheet for connection to the LD. An "O-ring" of thin-wall, 0.32cm-diam surgical tubing was attached to the outer edge of the she日t with a silicone rubber sealant (commonly called RTV and available from General Electric or Dow Corning) that vulcanizes at room temperature. The ends of the tubing were also joined with RTV. A layer of metal screen was placed between the rubber sheet and the vessel surface so that any helium from a leak inside the seal could easily reach the nozzle and thereby the $L D$. For the larger suction plates, slits were cut in the screen to allow it to easily conform to the compound curves. Suction plates as large as 25 by $35 \mathrm{~cm}$ were used on relatively flat surfaces and on outside curves, while special shapes were made for inside curves. The surgical tubing proved to be quite amenable for use as an O-ring and was much better than any of the other materials tried (e.g., Viton and butaN). With this arrangement for the suction plates, background levels as low as $10^{-7} \mathrm{~atm}-\mathrm{cm}^{3} / \mathrm{s}$ could be attained. In all cases a calibrated helium leak was used to check the system before leak hunting. The system was used to check a portion of the vacuum vessel in which the leak was suspected, and a potential 
leak was isolated to an area of $5 \mathrm{~cm}^{2}$. This area was cinecked with dye penetrant and found to contain three pinholes; while these were being ground out, slag pockets were discovered in two of them. They were repaired by welding, after which no further leak was found in this area. Following this repair, the existence of at least one additional leak of the same magnitude close to this location was found, but we have chosen to defer localizing the leak and repairing it until after the current operating period.

\section{Summary}

ATF is now in its fourth successful operating period. Much experience has been gained in cleaning and conditioning the vacuum vessel for plasma operation. This has resulted in significant improvements in plasma performance. A technique has been devised to find air leaks in the vacuum vessel that cannot be localized by conventional methods, since they are located in areas that are almost impossible to access from outside the vacuum vessel. Plans for the future include detection, localization, and repair of all leaks and the installation of additional getter sources to provide greater pumping in order to further reduce plasma impurities to levels even lower than those now being obtained.

\section{References}

1P. K. Mioduszewski et al., J. Nucl. Mater. 162-164, 825 (1989).

${ }^{2}$ R. C. Isler et al., Nucl. Fusion 29, 1381 (1989).

3J. F. Lyon et al., Fusion Techncl. 10, 179 (1986).

${ }^{4}$ R. A. Langley et al., J. Vac. Sci. Technol. A 6,1288 (1988).

${ }^{5}$ R. A. Langley et al., "Recent Results on Cleaning and Conditioning the ATF Vacuum Vessel System," presented at the AVS Topical Conference on Surface Conditioning of Vacuum Systems, Los Angeles, April 1989 (to be published in 
AIP Conf. Proc.); R. A. Langley et al., "Wall Conditioning in ATF," presented at the 7th International Workshop on Stellarators (proceedings to be published by the Intermational Atomic Energy Agency as an IAEA-TECDOC report).

6J. E. Simpkins and P. K. Mioduszewski, J. Vac. Sci. Technol. 20,1321 (1982).

7J. E. Simpkins ot al., J. Vac. Sci. Technol. A 1,1306 (1983).

${ }^{8}$ D. J. Santeler, private communication, 1999.

${ }^{9}$ R. W. Callis et al., J. Vac. Sci. Technol. A 3, 538 (1985).

${ }^{10} \mathrm{~S}$. W. Schwenterly et al., "Location and Repair of Air Leaks in the ATF Vacuum Vessel," in Proceedings of the 13th Symposium on Fusion Engineening, Knoxville, 1989 (Institute of Electrical and Electronics Engineers, New York, 1989), Vol. 2, p. 978. 
Table I. Pertinent surface areas

(SRF = surface roughness factor)

Plasma-facing

area $\left(\mathrm{m}^{2}\right)$
50 Stainless steөl

Thomson scattering viewing

\section{system}

Anodized aluminum

Stainless steel
0

0

0.2

0.06

100

10
Outgassing

SRF $\quad \operatorname{area}\left(10^{3} \mathrm{~m}^{2}\right)$

\section{Limiters}

AXF-5Q

Graphite diagnostic plate

ATJ

ICRF antenna shield

AXF-50

0.15

10

3

0.1

0.5 
Table II. Estimated $\mathrm{H}_{2} \mathrm{O}$ released from

Thomson scattering viewing system

(Bake cycle duration: $5 \times 104 \mathrm{~s}$, maximum bake temperature: $150^{\circ} \mathrm{C}$ )

Baking cycle

Gas released (Torr-L)

1
2
3
4

1000

300

50

1 
Figure captions

FIG. 1. Geometric configuration of the ATF vacuum vessel.

FIG. 2. Schematic of the ATF vacuum vessel, major internal components, and pumping system.

FIG. 3. Pressure response during the second bake cycle following a vacuum vessel opening.

FIG. 4. Maximum pressure reached during baking of the Thomson scattering viewing system for a series of bake cycles in ATF.

FIG. 5. Time from beginning of neutral beam injection to radiative collapse.

FIG. 6. Peak stored energy in the plasma. 
OANL - DWG 85 - 3623A FED

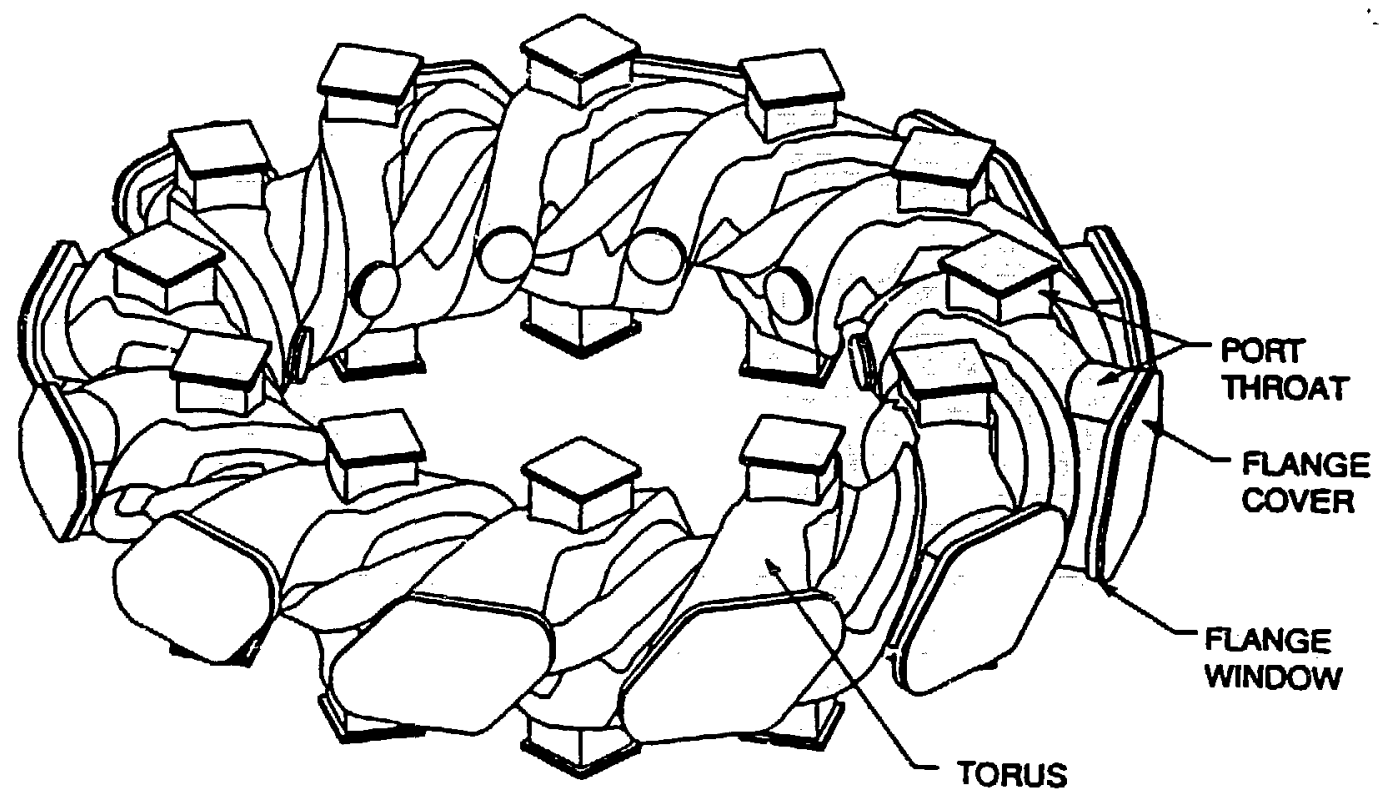




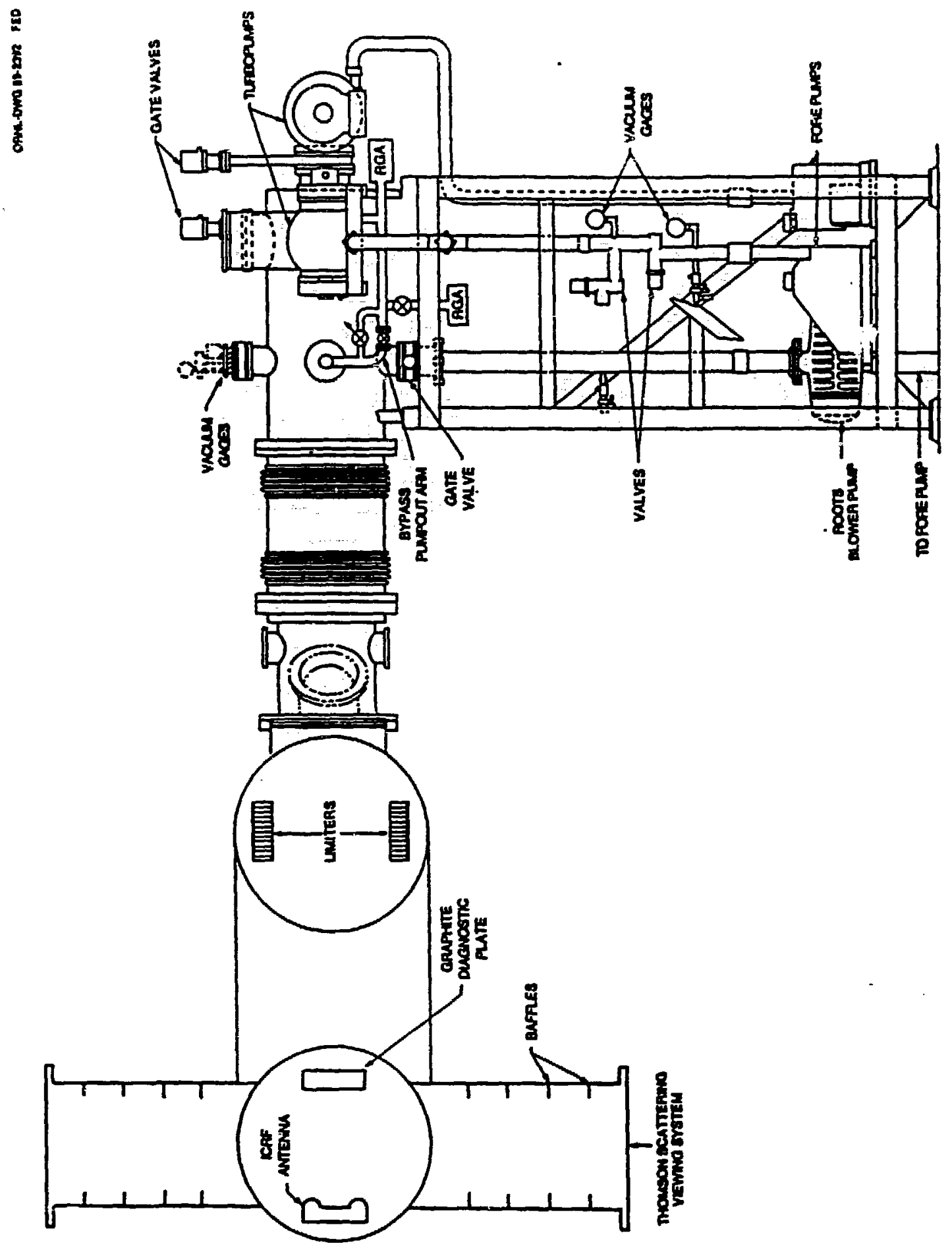




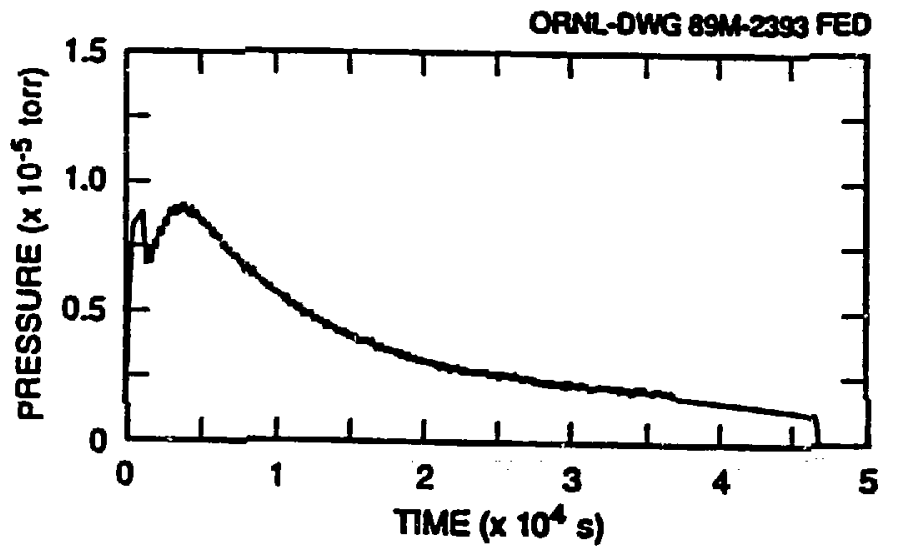




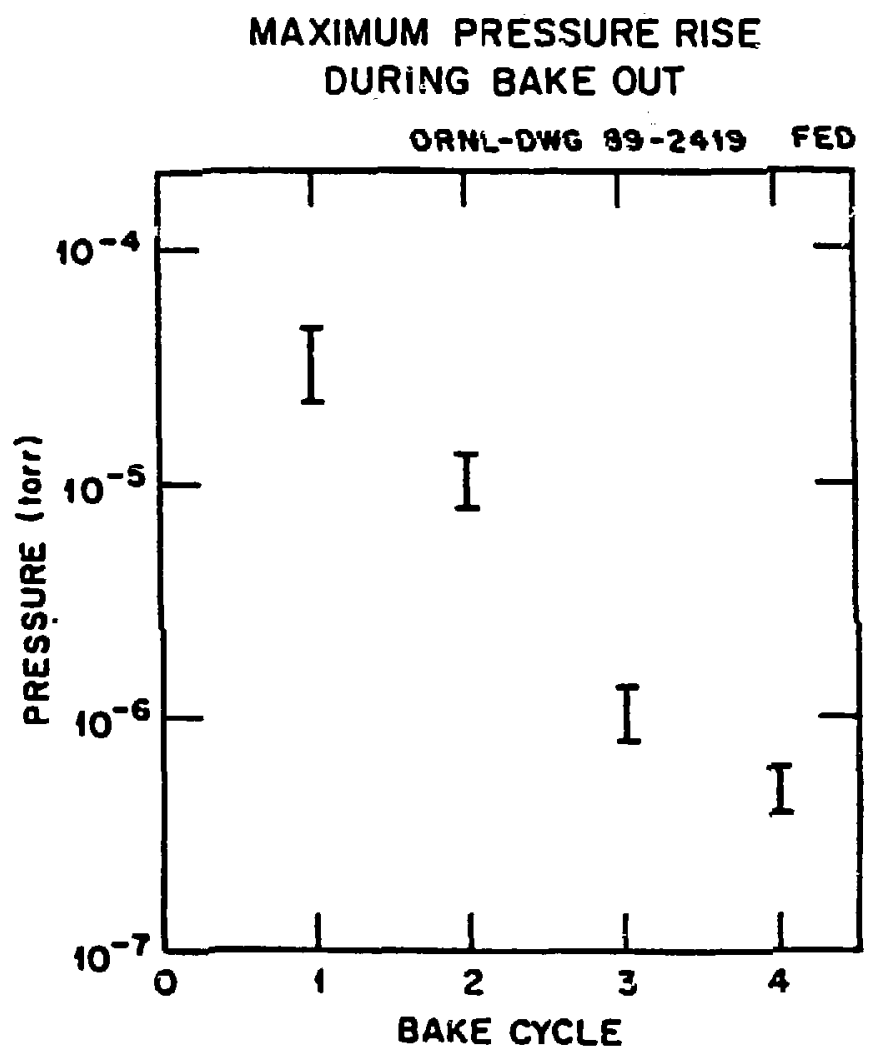




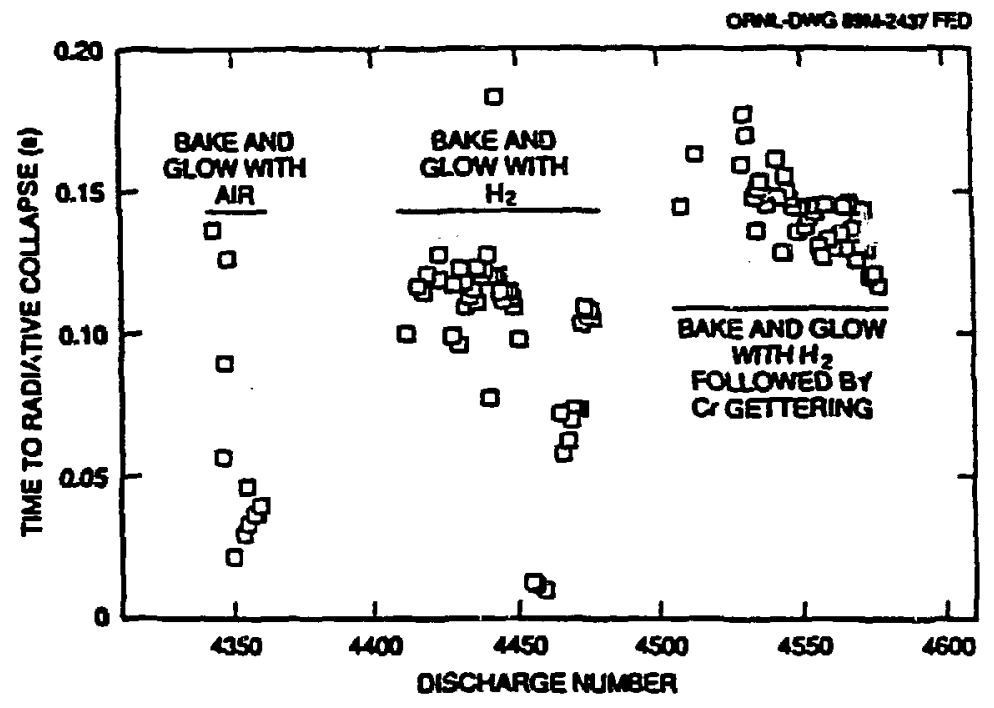




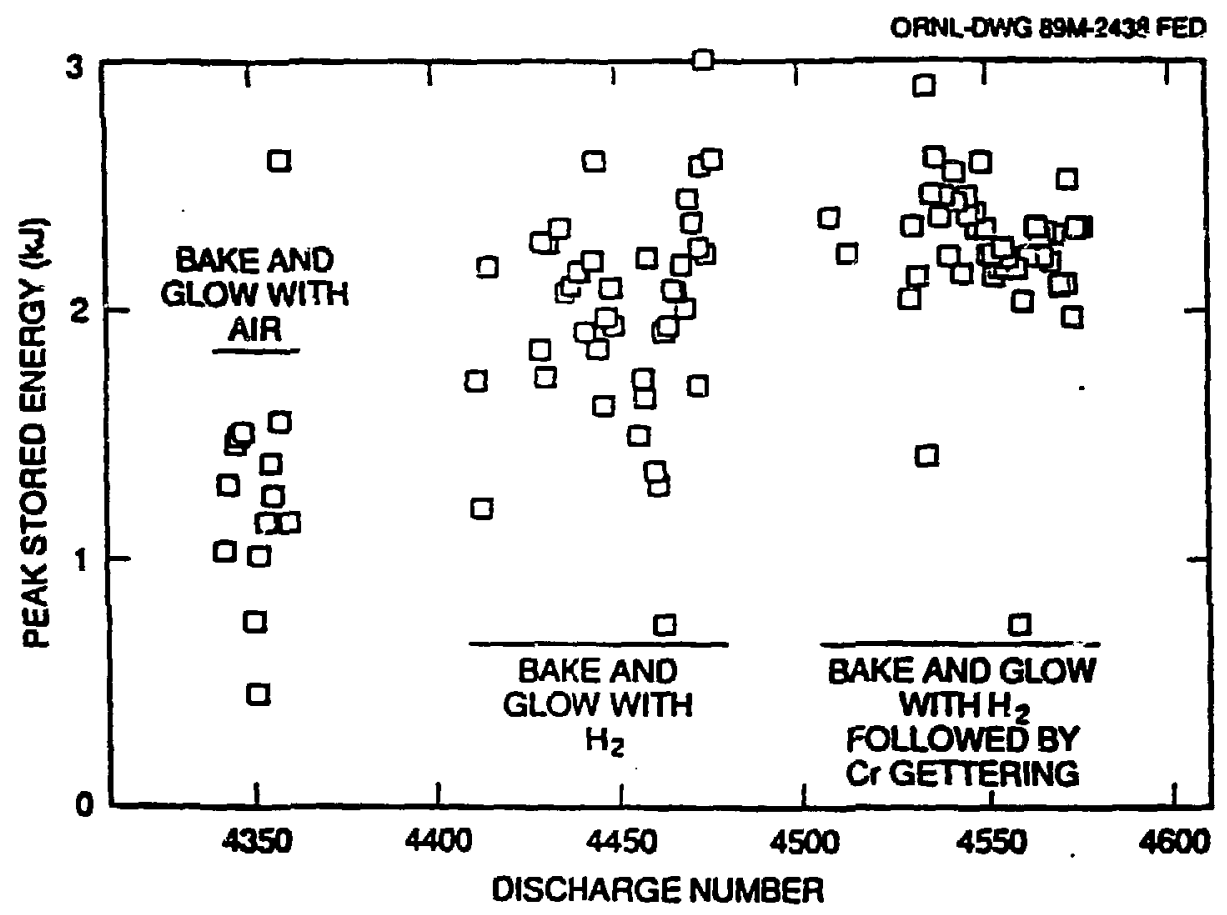

